\title{
Awareness of undergraduate dental students at Taibah University toward early detection of oral
}

\section{cancer}

\begin{abstract}
The aim of this study is to determine level of oral cancer awareness by assessing dental students' awareness of etiology, risk factors, diagnosis, and management of oral cancer. A total of 70 undergraduate dental students at Taibah University, from third to fifth years, enrolled in a cross-sectional study during June 2013 academic year by filling in a questionnaire assessing their knowledge of oral cancer. Data were piled up and analyzed using SPSS version 20. Our results revealed that most of students recognized tobacco as a major risk factor for oral cancer. Regarding intra-oral site, $61 \%$ of students' distinguished tongue as the most common site. Concerning clinical signs, more than half of fourth year students were able to identify non-homogenous leukoplakia and erythroplakia as putative oral cancer signs. Overall, this study revealed quite unsatisfactory level of awareness concerning oral cancer among undergraduate dental students. This implies the necessity to improve dental education programs to enhance knowledge of oral cancer risk factors and early detection concepts.
\end{abstract}

Keywords: oral cancer early detection, risk factors, dental students, tobacco, tongue, questionnaires
Volume 5 Issue 2 - 2016

\author{
Basant Hamdy, ${ }^{1,2}$ Asim Almarhoumi, ${ }^{3}$ Eman A \\ Arnout ${ }^{2,4}$ \\ 'Department of Oral Pathology, Faculty of Dentistry, Tanta \\ University, Tanta, Egypt \\ ${ }^{2}$ College of Dentistry, Taibah University,Al- Madinah AI \\ Munawarah, KSA \\ ${ }^{3}$ Department of Orthodontics, Faculty of Dentistry, Taibah \\ University, Al- Madinah Al Munawarah, KSA \\ ${ }^{4}$ Department of Oral Medicine, Periodontology, Diagnosis and \\ Oral Radiology, Faculty of Dentistry, Ain Shams University, Cairo, \\ Egypt
}
Correspondence: Eman A Arnout, Oral Radiology Assistant Professor, Department of Oral Medicine, Periodontology, Diagnosis and Oral Radiology, Faculty of Dentistry, Ain Shams University, Cairo, Egypt, Tel +201002500 I84, Email emanarnooo@gmail.com

Received: August 27, 2016 | Published: September 28, 2016

\section{Introduction}

Oral cancer incidence is increasing worldwide in the last decades. ${ }^{1}$ Although it is known to be a disease of elderly, younger patients are also affected. ${ }^{2}$ In a demographic study conducted in Jeddah/ KSA for 10 years, $25 \%$ of diagnosed neoplastic lesions revealed to be malignant; which is considered a relatively alarming percentage. ${ }^{3}$ Among the US and European countries, the tongue is the most common site for intraoral cancer, whereas buccal mucosa is the common site of Asian population. The floor of the mouth, gingiva and palate are other less commonly affected sites ${ }^{4}$ about $95 \%$ of diagnosed mouth cancers are oral squamous cell carcinoma (OSCC). Oral cancer is a multifactorial disease, with tobacco smoking and alcohol drinking being the main risk factors. Although oral cancer is usually symptomatic, the initial lesion is almost symptomless and often passed unnoticed to the patient. Furthermore, ignorance of early signs of oral cancer can delay clinical presentation and referral which, therefore, adversely increase morbidity and mortality rates. ${ }^{5}$ Preceding studies have reported the lack of oral cancer awareness amongst doctors and dentists, particularly among medical and dental students. ${ }^{1-5}$ It has been reported that there is an increased need for undergraduate dental students to be educated and trained in the identification of signs and symptoms of oral pre-malignancy and malignancy in addition to early patient's management. Prevention is, therefore, possible by spreading awareness. ${ }^{1}$ The aim of this study is to determine the level of oral cancer awareness by assessing the knowledge of undergraduate dental students regarding etiology, risk factors, diagnosis, and management of oral cancer.

\section{Material and methods}

A cross-sectional questionnaire-based study was performed on 3rd, 4th, and 5th-year undergraduate dental students, studying in both female and male sections, at Taibah University. The present study was reviewed by the Taibah University College of Dentistry, Research Ethics Committee (TUCD REC). Waiver of Informed Consent was requested based on the nature of the tool used being a self-administered anonymous questionnaire. An introductory section was added describing the aim of the study, name of and contact details of the Investigators for the male and female section, the benefit of the study in addition to voluntary participation in the research. The self-administered questionnaire was formulated according to Brzak et al., ${ }^{6}$ and Colella et al., with slight modifications. Pilot testing of the questionnaire was performed to test validity and reliability of the study tool. Firstly, the study sample was classified according to gender, age and academic year, thus we were sure that all enrolled samples had previously studied oral pathology course. The questionnaire comprised of eight multiple choice questions, four yes or no questions and two direct questions and was handed to the dental students. The questionnaire was divided into three sections:

a. The first section (questions 1 to 3 ) aimed at assessing students' attitude towards regular examination and screening of the oral cavity.

b. The second section (questions 4 to 9) evaluated dental students knowledge concerning oral cancer risk factors, common sites, clinical signs, and their attitude towards referral of cancer patients.

c. The third section (questions 10 to 12) estimated students' satisfaction with a level of oral cancer knowledge gained throughout their academic study.

d. Finally, two open-end questions assessed students' perception regarding possible means of oral cancer prevention and early detection.

\section{Statistical analysis}

Data were collected, coded and analyzed using IBM SPSS software version 20 under Windows 7. Descriptive analysis followed by inferential statistics were done using Fisher exact test to compare between groups. P value of 0.05 was considered as a cut off point for the level of significance.

\section{Results}

Questionnaires were returned by all targeted students attended at the time of initial delivery. Mean age, sex distribution and the number of respondents per academic year are shown in (Table 1). The overall response rate for 
questions ranged from $42.9 \%$ to $100 \%$ with a mean percentage of $84.6 \%$. Of these, the two open-ended questions number 13 and 14 yielded the lowest response with an overall percentage of $44.3 \%$ and $42.9 \%$ respectively. Also, it is noteworthy that amongst the multiple-choice questions, only the third question showed the least response rate with the overall percentage of $47.1 \%$. Since there were no significant differences between students regarding their academic year or sex, only answers that showed differences of interest were emphasized (Table 2). Students of all groups responded positively to the first question, 'Do you thoroughly examine the oral mucosa of your patients?' (Yes or No), with a percentage of $85.5 \%$ regarding question 4 , 'What would you consider a risk factor for oral cancer?' There was no statistically significant difference between students' groups in recognizing tobacco as a risk factor for oral cancer (95.7\% of total students). Yet, significantly more fourth-year students were able to identify alcohol as risk factors compared to fifth-year students (fourth year 72.4\%, fifth-year 6.25\%, p < 0.05) (Table 2) (Figure 1).

Table I Age and gender distribution of student respondents (number and percentages)

\begin{tabular}{lllll}
\hline \multirow{2}{*}{ Student year } & Frequency and Percentage & Age Mean \pm Std. & \multicolumn{2}{l}{ Gender } \\
\cline { 4 - 5 } & & & Male & Female \\
\hline 3rd year & $25(35.7 \%)$ & $21.3 \pm 0.82$ & II (44) & $14(56)$ \\
4th year & $29(41.4 \%)$ & $22.5 \pm 0.63$ & $15(51.7)$ & $14(48.3)$ \\
5th year & $16(22.9 \%)$ & $23.55 \pm 0.93$ & $16(100)$ & - \\
\hline
\end{tabular}

Table 2 The questionnaire questions and dental student's answers

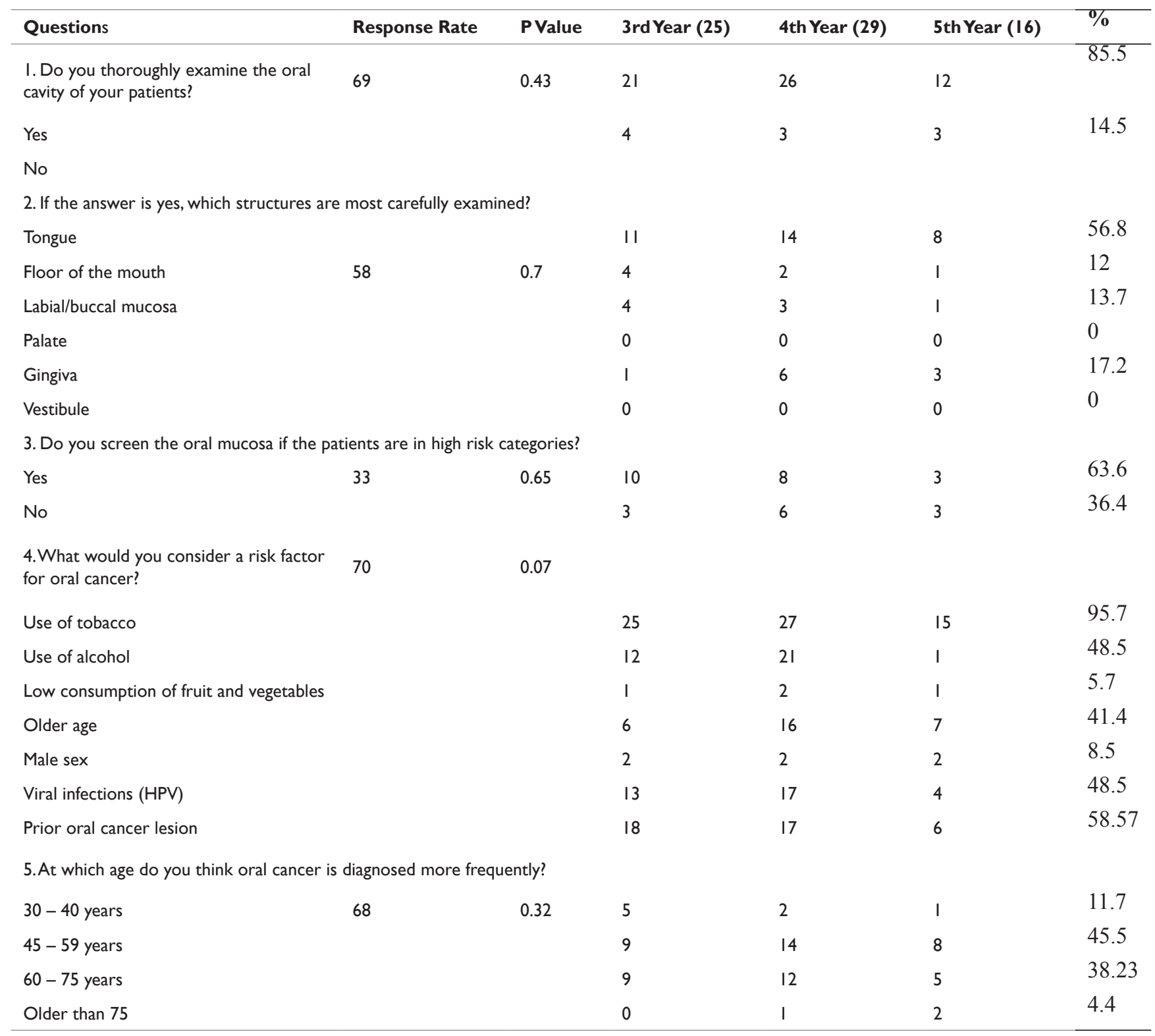


Table Continued...

\begin{tabular}{|c|c|c|c|c|c|c|}
\hline Questions & Response Rate & P Value & 3rd Year (25) & 4th Year (29) & 5th Year (16) & $\%$ \\
\hline $\begin{array}{l}\text { 6. What do you believe is the most } \\
\text { common site for oral cancer? }\end{array}$ & 69 & 0.08 & & & & \\
\hline Tongue & & & 17 & 18 & 9 & 63.7 \\
\hline Floor of the mouth & & & 6 & 10 & 4 & 28.98 \\
\hline Gingiva & & & 0 & 0 & I & 1.4 \\
\hline Labial/buccal & & & 0 & $\mathrm{I}$ & 0 & 1.4 \\
\hline Palate & & & 0 & 0 & । & 1.4 \\
\hline Vestibule & & & 1 & 0 & 1 & 2.8 \\
\hline \multicolumn{7}{|c|}{ 7.As regard the clinical appearance of oral cancer, do you feel? } \\
\hline Very well-informed & 66 & 0.15 & 1 & 2 & 1 & 6 \\
\hline Well-informed & & & 4 & 8 & 5 & 25.7 \\
\hline Adequately informed & & & 15 & 6 & 6 & 40.9 \\
\hline Poorly informed & & & 3 & 10 & 4 & 25.7 \\
\hline \multicolumn{7}{|c|}{ 8. What changes in the mouth would drive you to suspect oral cancer? (You can tick more than one) } \\
\hline $\begin{array}{l}\text { Ulceration non responsive to therapy of } \\
2 \text { weeks' duration }\end{array}$ & 69 & 0.42 & 24 & 25 & 13 & 89.9 \\
\hline Homogeneous leukoplakia & & & 6 & 4 & 0 & 14.5 \\
\hline Non-homogeneous leukoplakia & & & 17 & 19 & 9 & 65.2 \\
\hline Candidal leukoplakia & & & 9 & 6 & 5 & 28.9 \\
\hline Erythroplakia & & & 10 & 15 & 7 & 46.37 \\
\hline Oral lichen planus & & & 6 & 10 & 3 & 27.5 \\
\hline Candidiasis & & & 3 & 2 & 2 & 10.1 \\
\hline Hairy leukoplakia & & & 10 & 7 & 5 & 31.8 \\
\hline Other (define: ................................ & ....) & & 0 & 0 & 0 & 0 \\
\hline \multicolumn{7}{|c|}{ 9.When you are graduated, to whom would you refer a patient when you suspect an oral malignancy? } \\
\hline Plastic surgery specialist & 69 & 0.001 & 0 & 0 & 0 & 0 \\
\hline Otolaryngologist & & & 0 & 0 & 0 & 0 \\
\hline Oral \& maxillofacial surgeon & & & 2 & 4 & I & 10.1 \\
\hline Oral medicine specialist & & & 10 & 22 & 7 & 56.5 \\
\hline Oncology specialist & & & 17 & 5 & 8 & 43.47 \\
\hline General practitioner & & & 0 & 0 & 0 & 0 \\
\hline Other dentist & & & 0 & 0 & 1 & 1.4 \\
\hline \multicolumn{7}{|c|}{ I0. Do you feel that you have enough information concerning prevention and management of oral cancer? } \\
\hline Yes & 70 & 0.15 & 12 & 20 & 12 & \\
\hline No & & & 13 & 9 & 4 & 37.14 \\
\hline \multicolumn{7}{|c|}{ II.Would you like to get much knowledge or teaching on oral cancer and potentially malignant lesions? } \\
\hline Yes & 70 & 0.48 & 22 & 22 & 12 & 80 \\
\hline No & & & 3 & 7 & 4 & 20 \\
\hline
\end{tabular}


Table Continued...

\begin{tabular}{|c|c|c|c|c|c|c|}
\hline Questions & Response Rate & P Value & 3rd Year (25) & 4th Year (29) & 5th Year (16) & $\%$ \\
\hline \multicolumn{7}{|l|}{ 12.Which format would you prefer? } \\
\hline Information package & & & 4 & 2 & 5 & 19.2 \\
\hline Continuous education lectures & 57 & 0.12 & 7 & 4 & I & 21 \\
\hline Seminars & & & 8 & 5 & 2 & 26.3 \\
\hline Webinars & & & I & I & I & 5.2 \\
\hline Participation in organized research & & & 2 & 10 & 4 & 28 \\
\hline Other (define: ......................... & $(\ldots \ldots)$. & & 0 & 0 & 0 & 0 \\
\hline \multicolumn{7}{|c|}{ 13.What do you know about early detection of oral cancer, that is, what does it involve? } \\
\hline clinical exam & 31 & 0.52 & I & 5 & 1 & 22.5 \\
\hline biopsy & & & I & 1 & I & 9.6 \\
\hline regular checkup & & & 0 & 3 & I & 12.9 \\
\hline family history & & & I & 0 & 0 & 3.2 \\
\hline Patient education & & & I & 0 & 0 & 3.2 \\
\hline Wrong answer & & & 4 & 6 & 5 & 48.3 \\
\hline \multicolumn{7}{|c|}{ 14.What is meant by prevention of oral cancer, that is, what does it involve? } \\
\hline Community education & 30 & 0.22 & 2 & 7 & 3 & 40 \\
\hline Avoid risk factor & & & 2 & 7 & 3 & 40 \\
\hline Regular checkup & & & I & 3 & 5 & 30 \\
\hline Good oral hygiene & & & I & 1 & 0 & 6.6 \\
\hline Wrong answer & & & 2 & 0 & I & 10 \\
\hline
\end{tabular}

\section{Risk Factors of Oral Cancer}

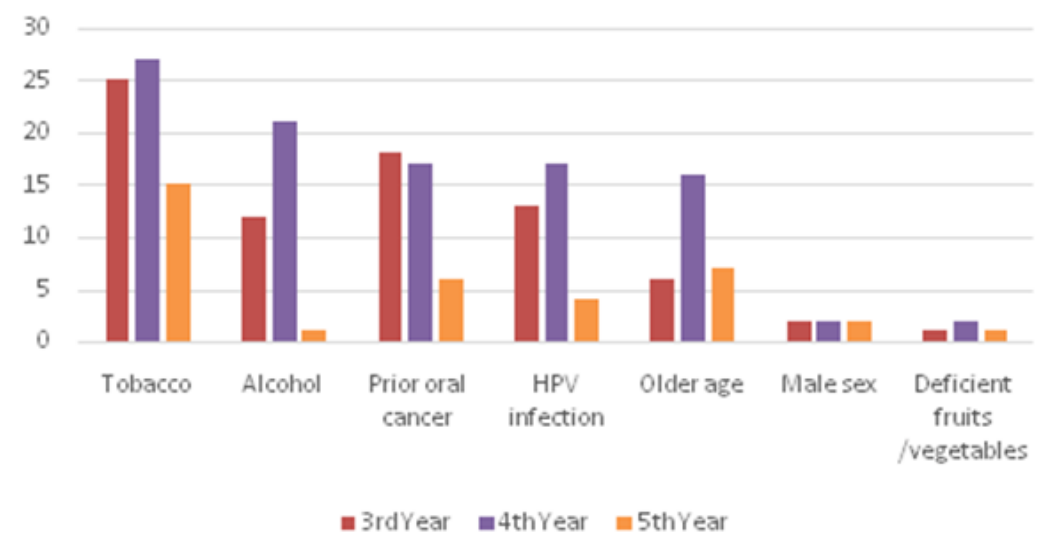

Figure I Distribution of answers among dental student years identifying oral cancer risk factor.

The majority of students distinguished tongue as the most common site for oral cancer (61\%) (Figure $2 \& 3$ ) and chronic ulceration, resistant to therapy as the main suspicious clinical sign $(86 \%)$. However, the fourth year students showed a better ability to identify non-homogenous leukoplakia (fourth year $65.5 \%$, third year $65 \%$, and fifth-year $56 \%$ ) and erythroplakia (fourth year $51.7 \%$, third year $40 \%$, fifth-year $43.7 \%$ ) as putative signs for oral cancer (Table 2). Considering referral of suspected oral cancer patients, there was a significant difference $(p<0.05)$ between students of the fourth year who preferred referral to oral medicine specialist $(75.86 \%)$ and those of third and fifth year students who selected referral to oral medicine specialist and oncology specialist (third year 54\%, fifth-year 46.87\%) (Figure 4). The majority of students in all groups $(61.1 \%)$ felt they have enough information concerning oral cancer prevention and management; nevertheless, most of them $(77.7 \%)$ cared about getting much knowledge on oral malignancy and potentially malignant lesions (Table 2 ).

As regards the open-ended question, "What do you know about early detection of oral cancer, that is, what does it involve?", Half of the respondents (50\%) didn't give relevant answers. Only $23.3 \%$ emphasized the importance of clinical examination to detect early mucosal changes in addition to applying various screening tests (Figure 5\&6). On the other open-ended question, "What is meant by prevention of oral cancer, that is, what does it involve?", $38.7 \%$ of respondents referred to community education and avoidance of 
oral cancer risk factors. Of note, there was a significant difference $(\mathrm{P}=0.005)$ between responses of male and female students; that is $60 \%$ of female students focused on elimination of risk factors especially smoking and alcohol as well as improvement of oral hygiene, whereas $43.5 \%$ of male students focused on educating community about oral cancer risk (Figure 5\&6).

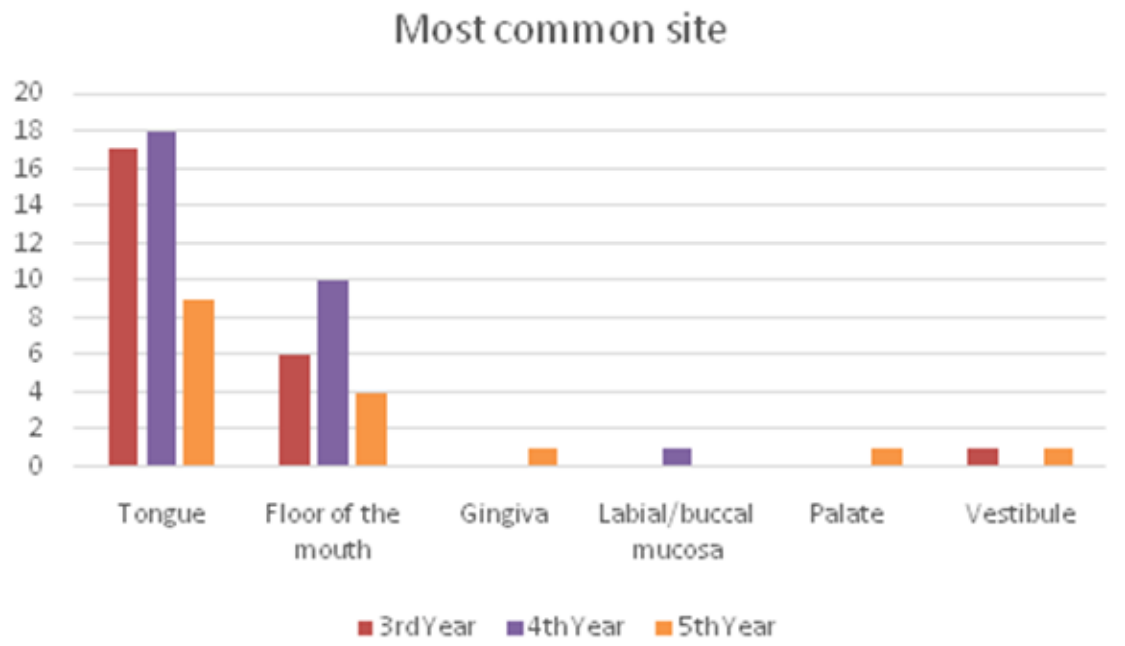

Figure 2 Distribution of answers among dental student years regarding oral cancer common sites.

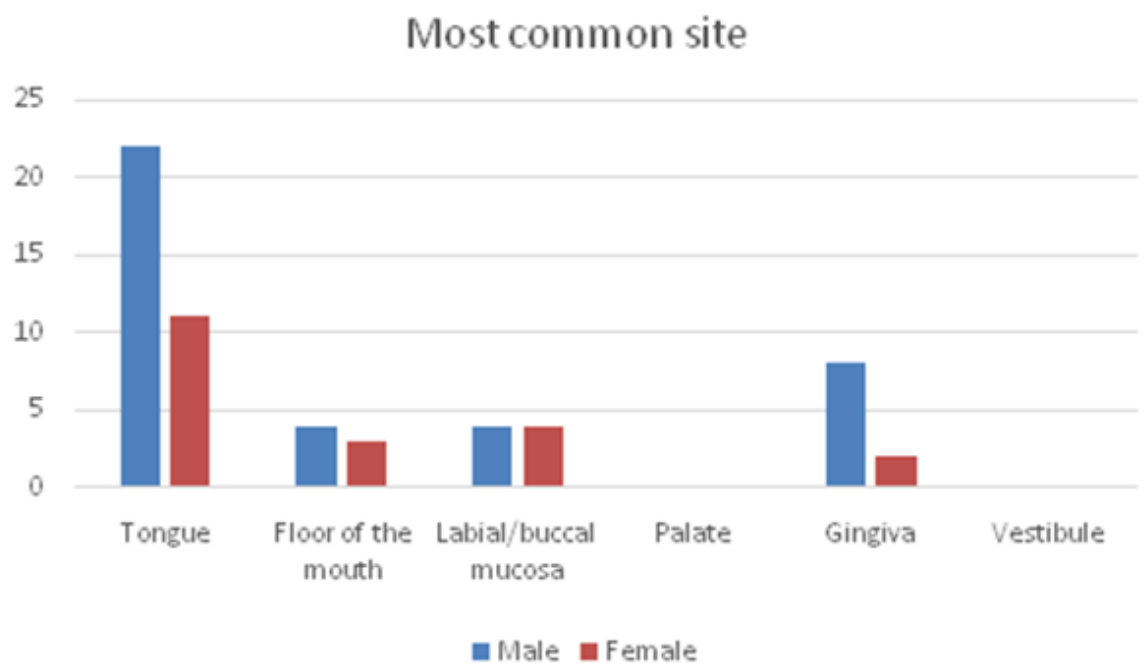

Figure 3 Distribution of answers among dental student male and female regarding oral cancer common sites.

\section{Suspected Oral Cancer Patient Referral}

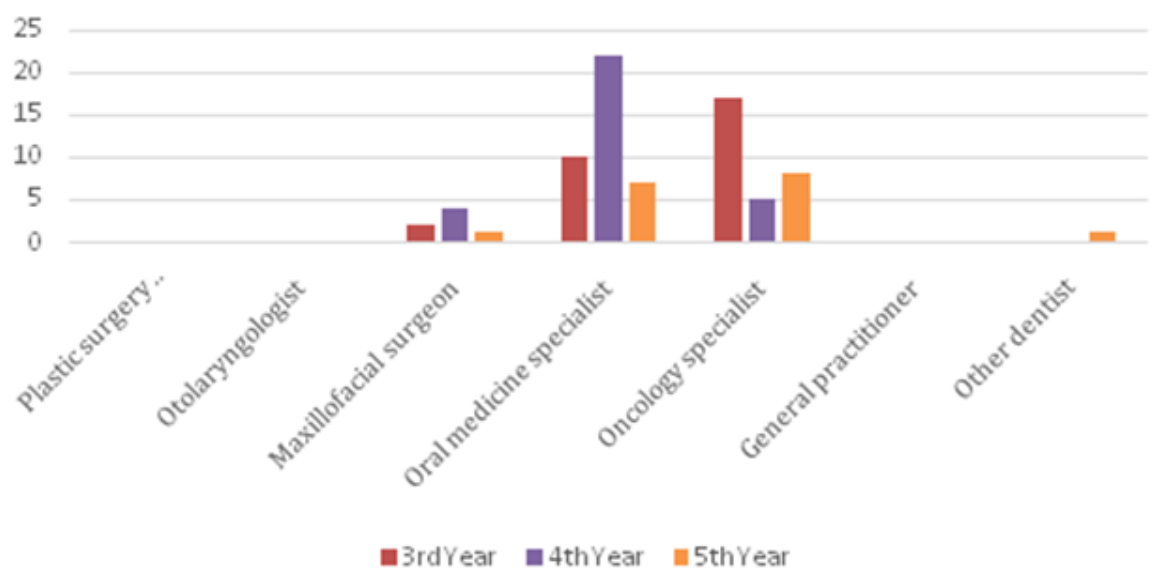

Figure 4 Point of referral chosen by dental students at different years. 


\section{Early detection of oral cancer}

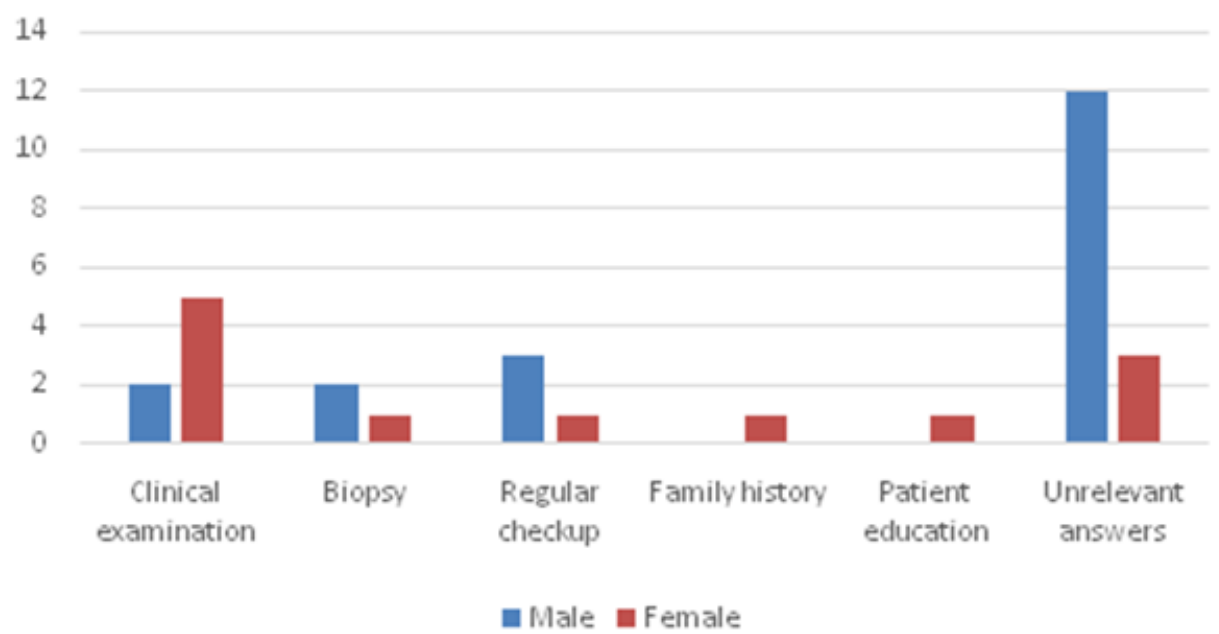

Figure 5 Distribution of answers among different genders for dental student to the open ended question:What does early detection of oral cancer involve?

\section{Prevention of Oral Cancer}

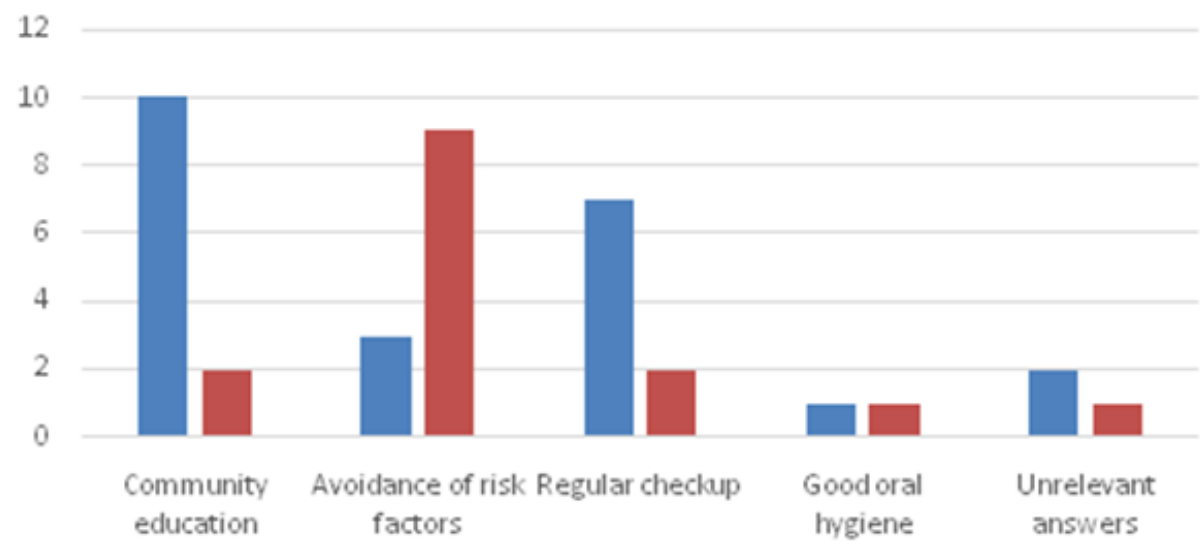

- Male a Female

Figure 6 Distribution of answers among different genders for dental student to the open ended question: what does prevention of oral cancer involve?

\section{Discussion}

It is of crucial importance that undergraduate dental students grasp adequate knowledge about early diagnosis and referral of oral cancer patients. This knowledge endows students the ability to detect cancerous lesion on its very early stage, which brings about better patient outcome. Our study reports Taibah dental students' attitude towards regular oral cavity examination and screening, as well as overall knowledge concerning oral cancer risk factors, common sites, clinical signs and referral of cancer patients. The results of this study offer a comprehensive view concerning status of knowledge and behavior among undergraduate dental students. A considerable cohort of undergraduate students cared for regular examination and screening of the oral cavity. As $85.5 \%$ of the students positively replied that, they did a thorough examination of the oral cavity, and $63.6 \%$ agreed for screening oral mucosa in high-risk patients. Also, $56.8 \%$ of the student plotted that the tongue is the site that should be carefully examined. Similarly, in Malaysia $96.7 \%$, in Carter and Ogden $72.46 \%$, and in Shimla/India $89.7 \%$ of dental students affirmatively replied that they do routine oral mucosa examination. Additionally, our results are comparable to results by Brzak, Awan \& Fotedar et al., ${ }^{6-8}$ who reported that the majority of dental students under study routinely examine oral mucosa). ${ }^{7-9}$ In the present study, the majority of students were able to identify tobacco $(95.7 \%)$ as the principal risk factor for oral cancer. Moreover, (58. 5\%) considered past history of previous oral cancer lesion would represent a major factor. Unfortunately, almost more than half of the students $(51.5 \%)$ did not recognize human papillomavirus (HPV) or alcohol consumption as evolving oral cancer risk factors. The same trend was reported in Malaysia, where $84.4 \%$ of dental identified tobacco consumption as a risk factor for oral cancer, but lesser percentage was going for alcohol consumption $35 \% .{ }^{8}$ In accordance with our results, a previous study was done to assess oral cancer awareness of Romanian undergraduate dental students; they found that $96.8 \%$ recognized tobacco as the first oral cancer risk factor, unlike our results a higher percentage was found for previous oral cancer lesion $(85.1 \%)$, and alcohol consumption (77.7\%). ${ }^{10}$ Higher values were also reported in Kuwait, where $98.6 \%$ of undergraduate dental students identified the use of tobacco and alcohol $(76.7 \%)$ as the principal risk factors for oral cancer. ${ }^{11}$

Alcohol consumption is supposed to play a role as a causative factor of oral cancer and this should be emphasized in future teaching of undergraduate dental students. In addition, Human papilloma virus vaccination showed promising results in oral cancer prevention. ${ }^{12,13}$ Thus, dental students should be 
prepared to play a role in public health awareness regarding explanation of the potential burden of sexually transmitted viruses as HPV, its role in oral cancer and importance of vaccination. In the present study, only $5.7 \%$ of the students identified Low consumption of fruit and vegetables potential oral cancer risk factor. Dental students should be informed about the protective role of fruit and vegetable consumption. A diet rich in antioxidants and phytonutrients as in whole grain food, vegetables, and fruits facilitate prevention of cancer progression. Moreover, "dietary supplements (vitamins, minerals, and bioactive compounds) should not be substituted for fresh fruit and vegetable consumption". ${ }^{11,14}$ Our results showed that $63.7 \%$ of the students successfully identified tongue as the most common site of oral cancer. Furthermore, $89.9 \%$ contemplated that chronic oral ulceration, irresponsive to treatment is of the highest suspect to oral cancer consistent with previous study by Colella et al. ${ }^{5,6}$ Additionally, more than half of fourth year students were able to identify nonhomogeneous leukoplakia and erythroplakia as potential oral cancer signs. It has been documented that about $51 \%$ of erythroplakia showed invasive carcinoma histopathologically and that comparable malignant transformation rates are reported for non-homogeneous leukoplakia. The good knowledge of these oral changes by fourth year students could be attributed to curricular modifications.

Referral to oral medicine specialist was the mostly preferred choice by students when they suspect a patient with oral cancer. This is analogous to findings of Carter et al., ${ }^{1}$ and Ogden ${ }^{5}$ who found that oral medicine was the most frequently selected point of referral. Such preference can be explained by the availability of oral medicine specialty at Taibah Dental Hospital which also precludes its generalization to other regions without a dental hospital. The unexpected results of the present study were that $80 \%$ of the students positively respond to the question that asks if they need more knowledge or oral cancer education. This finding should be seriously taken into concern and continuous improvement in oral cancer education via lessons, seminars, clinical sessions as well as enrollment in oral cancer prevention programs should be encouraged.

\section{Conclusion}

Since the incidence of oral cancer is still rising worldwide in the last years, the role of dental practitioners in early detection and prevention of such morbid disease is increasingly important. This study revealed quite unsatisfactory level of awareness concerning oral cancer among undergraduate dental students and this entails the necessity to improve dental students' knowledge about early detection of potentially malignant and oral cancer lesions via upgrading the theoretical and practical curricula as well as emphasizing participation in organized oral cancer prevention programs.

\section{Funding}

None.

\section{Acknowledgments}

None.

\section{Conflicts of interest}

Authors declare that there is no conflict of interest.

\section{References}

1. Carter LM, Parsonage Grant S, Marshall A, et al. Oral cancer teaching of medical students in the UK: time for a new approach? J Cancer Educ. 2011;26(2):308-314.

2. Johnson N. Tobacco use and oral cancer: a global perspective. J Dent Educ. 2001;65(4):328-339.

3. Al Yamani AO, Al Sebaei MO, Bassyoni LJ, et al. Variation of pediatric and adolescents head and neck pathology in the city of Jeddah: A retrospective analysis over 10 years. Saudi Dent J. 2011;23(4):197-200.

4. Kujan O, Alzoghaibi I, Azzeghaiby S, et al. Knowledge and attitudes of Saudi dental undergraduates on oral cancer. $J$ Cancer Educ. 2014;29(4):735-738

5. Colella G, Gaeta GM, Moscariello A, et al. Oral cancer and dentists: Knowledge, attitudes, and practices in Italy. Oral Oncol. 2008;44(4):393-399.

6. Lončar Brzak B, Canjuga I, Baričević M, et al. Dental students' awareness of oral cancer. Acta Stomatologica Croatica. 2012;46(1):50-58.

7. Awan KH, Khang TW, Yee TK, et al. Assessing oral cancer knowledge and awareness among Malaysian dental and medical students. Journal of Cancer Research and Therapeutics. 2014;10(4):903-907.

8. Fotedar S, Bhardwaj V, Manchanda K, et al. Knowledge, attitude and practices about oral cancers among dental students in HP Government Dental College, Shimla Himachal Pradesh. South Asian Journal of Cancer. 2015;4(2):65-67.

9. Dumitrescu AL, Ibric S, Ibric Cioranu V. Assessing oral cancer knowledge in Romanian undergraduate dental students. Journal of Cancer Education. 2014;29(3):506-513.

10. Joseph BK, Sundaram DB, Ellepola AN. Assessing oral cancer knowledge among undergraduate dental students in Kuwait University. Journal of Cancer Education. 2015;30(3):415-420.

11. Dost F, Do L, Farah CS. Lesion Evaluation, Screening and Identification of Oral Neoplasia Study: an assessment of high-risk Australian populations. Community Dentistry and Oral Epidemiology. 2016;44(1):64-75.

12. Daley E, Dodd V, De Bate R, et al. Prevention of HPV-related oral cancer: assessing dentists' readiness. Public Health. 2014;128(3):231-238.

13. Chainani Wu N, Epstein J, Touger Decker R. Diet and prevention of oral cancer: strategies for clinical practice. J Am Dent Assoc. 2011;142(2):166-169. 